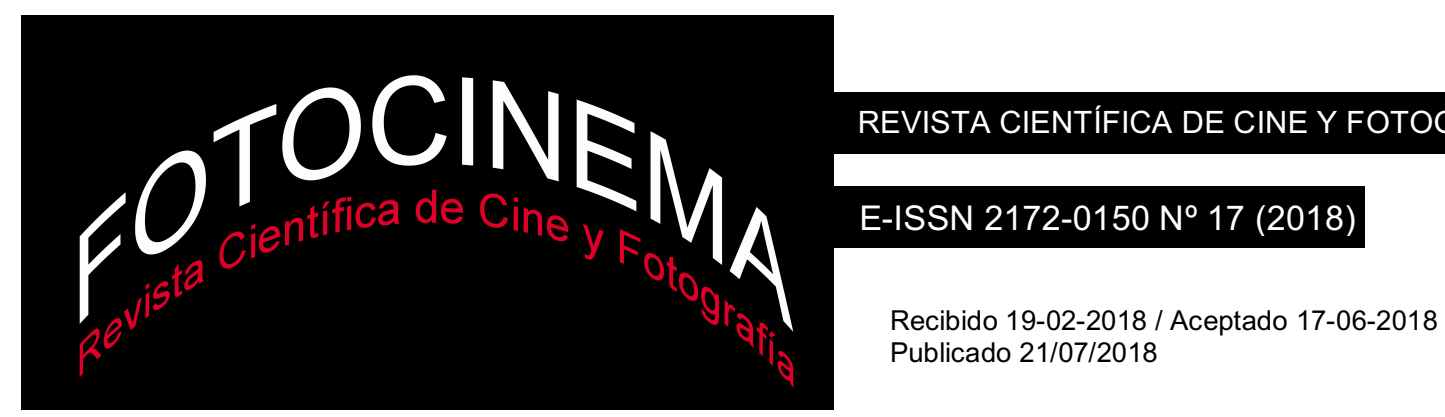

\title{
Sistematización, acumulación y proceso en la obra de tres fotógrafos andaluces: Clara González Ortega, Gabriel Campuzano y Juan Carlos Bracho
}

\section{Systematization, accumulation and process in the work of three andalusian photographers: Clara González Ortega, Gabriel Campuzano and Juan Carlos Bracho}

\author{
Alberto Estudillo-Ruiz \\ Universidad de Sevilla, España \\ albertoestudilloruiz@hotmail.com \\ Paco Lara-Barranco \\ Universidad de Sevilla, España \\ paco_lara@us.es
}

\begin{abstract}
Resumen:
Este artículo pretende contribuir a los estudios sobre fotografía contemporánea. Nuestra investigación analiza métodos de fragmentación, empleados para la conformación de imágenes: sistematización, acumulación y proceso. Centramos nuestro estudio en la obra de tres artistas del ámbito andaluz: Clara González Ortega, aborda conceptos de espacio y tiempo mediante una repetición sistemática de tomas fotográficas; Gabriel Campuzano, con la idea de archivo reordena la acumulación de las imágenes fotográficas para generar un nuevo discurso; y Juan Carlos Bracho, juega con el proceso que es la conjunción de un método sistemático y de acumulación. Haciendo uso de una metodología analítico-comparativa, nuestra principal conclusión subraya que la fragmentación permite establecer nuevas estrategias de representación para la imagen.
\end{abstract}

\begin{abstract}
:
This article aims to contribute to studies on contemporary photography. We focus our attention on fragmentation methods and it is used for shaping images: systematization, accumulation and process. We focus our studio on the work of three Andalusian artists: Clara González Ortega, who deals the concepts of space and time through a systematic repetition of photographic shots; Gabriel Campuzano that works with the archive idea for reordering the accumulation of photographic images and generating a new discourse; and Juan Carlos Bracho that works with the process as the conjunction of the systematic method and accumulation. We make use of an analytical-comparative methodology, our main conclusion emphasizes that the fragmentation through the different processes allows us to approach new strategies of representation.
\end{abstract}

Palabras clave:

fragmentación; sistematización; acumulación; proceso; fotografía.

Keywords:

Fragmentation; Systematization; Accumulation; Process; Photography. 


\section{Introducción}

La fotografía es un medio ambiguo y diverso. Desde la década de los años 60 artistas y teóricos del arte desarrollaron la idea de que la fotografía no posee una identidad fija y que, por el contrario, cambia a través del tiempo al estar determinada históricamente. Así, como resultado de la diversificación de sus usos el medio fotográfico ha sido reinventado y ampliado $\mathrm{y}$, por ello, para comprender su complejidad, debemos acometer su estudio a través de sus múltiples perspectivas.

Este artículo tiene como objetivos, primero, plantear la fragmentación como elemento propio del proceso fotográfico actual al constituir un recurso para las estrategias de sistematización, acumulación y proceso; y segundo, analizar el trabajo de los artistas andaluces Clara González Ortega, Gabriel Campuzano y Juan Carlos Bracho, por la estrecha relación de sus aportaciones fotográficas con estas estrategias. En el apartado 2. Fotografía y fragmentación abordamos el contexto posmoderno a través de la lógica de la fragmentación con modelos de representación de lo múltiple. En el apartado 3. Sistematización, acumulación y proceso analizamos los métodos de producción en diferentes artistas internacionales. Finalmente, en al apartado 4. Creación fotográfica en Andalucía llevamos a cabo una aproximación al trabajo fotográfico de los artistas andaluces mencionados arriba, por su relación con los métodos de fragmentación analizados anteriormente. En su conjunto, el texto no pretende elevar a los tres fotógrafos andaluces abordados en esta investigación a figuras reconocidas internacionalmente, es una evidencia que en el momento actual la presencia de sus obras en el panorama internacional no ocupa ese nivel. Constituye un hecho, sin embargo, que sí utilizan estrategias para la construcción de la imagen que cuentan con referentes internacionales (apartado 3). Estos referentes son traídos a este estudio en buena lógica para generar un contexto, un marco referencial, sobre el cual se sustenta, y permite clarificar, el análisis posterior de los autores andaluces estudiados (apartado 4). La metodología de análisis comparativo busca contribuir a la comprensión del objeto de estudio. Finalmente, las conclusiones del estudio subrayan que la 
fragmentación es un recurso de gran fuerza expresiva para la construcción de discursos posmodernos.

\section{Fotografía y fragmentación}

La posmodernidad se ha instaurado en lo diferente, en lo heterogéneo. El momento actual está marcado por el dinamismo y el desplazamiento acelerado de todo lo que acontece. El filósofo y sociólogo Jean-Fraçois Lyotard, argumenta la imposibilidad de creer en el gran relato que había configurado la humanidad (Lyotard, 1994). Este gran relato o metarrelato, entendido como narración que tenía la función de legitimar la historia, ha dejado de tener validez, de ahí su incapacidad para justificar los acontecimientos históricos que tendrán lugar en el período Moderno. Como consecuencia, el nacimiento de la posmodernidad reacciona contra los grandes discursos totalizantes que habían definido la cultura occidental. A partir de este momento tiene lugar la fragmentación de la visión unitaria de la cultura, sustentada en una dinámica de constante destrucción y reconstrucción de los discursos en todas las esferas del conocimiento.

Fredric Jameson, filósofo y crítico, también refiere al signo que caracteriza a la sociedad de consumo posmoderna, inscrita en el capitalismo tardío: la fragmentación de los discursos culturales - de la propia realidad-, que define a través del "pastiche” o el lenguaje del simulacro. Así la organización espacial y temporal de la realidad es llevada a cabo por nuestra sociedad de forma inconexa e incoherente. Para Jameson, el tiempo y el espacio carecen de una organización coherente en la cultura posmoderna, y por lo tanto tienen como resultado lo fragmentario, lo heterogéneo y lo aleatorio (Jameson, 1996, pp. 4647).

A través de estos conceptos de fragmentación, multiplicación y simulacro la interpretación de la realidad es negada al sujeto posmoderno, este se diluye en lo que percibe de la misma, dado que la interpretación de la realidad no obedece a una única perspectiva. Por lo tanto, la realidad deja de ser única, uniforme y racional. Como auguró el filósofo francés Michel Foucault y confirman los 
filósofos posmodernos, el hombre se desvanece porque ha dejado de estar en el centro del discurso del conocimiento (Foucault, 1968, p. 314). Existe una dislocación del signo en relación con el objeto real. Por lo que ha dado lugar a su indefinición y fragmentación.

La fotografía juega un papel fundamental en el escenario artístico dentro del discurso posmoderno. La crítica posmoderna -Allan Sekula, Jo Spence, Rosalind Krauss, Victor Burgin, Abigail Solomon-Godeau, y Geoffrey Batchen, entre otros-, propone un conjunto de interpretaciones que consideran tanto los significados como los valores de cualquier imagen fotográfica absolutamente determinados por su contexto; argumentan que es la cultura la que determina el significado de las imágenes fotográficas. Desde este punto de vista, la fotografía carece de una identidad singular y de una historia unificada como sí proponía la crítica formalista, y, por ello, considerar una fotografía "como tal” no es más que una ficción engañosa. Dado que la fotografía oscila en el debate posmoderno entre lo histórico, lo político y lo estético, se presenta como una categoría ambigua, reflejo del mismo carácter ambiguo de la posmodernidad. Este debate se centra principalmente entre la cuestión epistemológica y la cuestión artística de la fotografía. Así, la crítica posmoderna defiende la fotografía como un concepto abierto, relacionado fundamentalmente con las ideas y los modos de pensar. De esta manera, la fotografía hoy se mezcla, se contamina y retroalimenta con otras disciplinas expresivas (pintura, dibujo, escultura, video...), hasta expandir la imagen. Tradicionalmente, la crítica formalista ha considerado al medio fotográfico como una herramienta documental que guarda la memoria de las vivencias humanas y sirve para autentificar un instante determinado.

Por este carácter 'ambiguo' y ‘contradictorio' la fotografía será utilizada por las tendencias conceptuales, desarrolladas en las segundas vanguardias del siglo XX. La inclusión del medio en el arte conceptual es explicada por Foster, Krauss, Bois y Buchloh (2006) como sigue:

Estos artistas introdujeron modelos de práctica fotográfica que también fusionaban estrategias del minimalismo, de la tardomodernidad y del Pop Art, manifiestamente derivadas de una comprensión más compleja de las 
implicaciones para la fotografía del readymade de Duchamp. [...] El medio en manos de esos artistas (post-Warhol y post-Ruscha), se convierte en una mera acumulación de huellas indiciales de imágenes, objetos, contextos, comportamientos o interacciones, en un intento de convertir la complejidad tanto de la dimensión arquitectónica del espacio público como de la dimensión social de interacción individual en tema de reflexión para el Arte Conceptual (Foster, Krauss \& Buchloh, 2006, p. 535).

Sobre la relación indicial que establece la fotografía con la realidad, el crítico y artista Robert C. Morgan expresa: "Lo significativo de la tendencia conceptual, no obstante, consistió en que a menudo esos fotodocumentos se convirtieron en la fuente «primaria» para reconstruir el sentido de la obra sobre la base de su intencionalidad” (Morgan, 2003, p. 122). Así pues, la fotografía se convierte en una herramienta de archivo, donde las "huellas indiciales" se constituyen en un registrado a priori 'sígnico' para, seguidamente, generar el significado. Anna María Guasch, profesora de Historia del Arte de la Universidad de Barcelona y crítica de arte, explica el modo en el que estos usos - las prácticas de archivoconstituyen modos de sistematización, acumulación y proceso como resultado de una pérdida de progresión lineal en los conceptos, es decir, el modelo de archivo lleva implícita su concepción fragmentada (Guasch, 2011, pp. 45-46). La utilización de la fotografía como archivo está fundamentada en las reflexiones de los filósofos franceses Jacques Derrida a través de su trabajo Mal de archivo. Una impresión freudiana (1977) y Michel Foucault con su obra La arqueología del saber (1979).

Para Derrida el archivo tiene como finalidad generar un sistema predeterminado mediante la selección previa de los diferentes elementos que lo componen: signos que conllevan una organización continua y sin deformación creada en un determinado lugar como consecuencia de un ejercicio de poder. "No hay archivo sin un lugar de consignación, sin una técnica de repetición y sin una cierta exterioridad. Ningún archivo sin afuera” (Derrida, 1997, p. 19). Esta 'exterioridad' es la que se encarga de situar el archivo en un lugar concreto y de su interpretación. Evidenciando de esto modo su carácter exterior, dado que el archivo se ha de consignar en algún "lugar exterior" para asegurar acciones como la memorización, la repetición, 
incluso la reproducción y la re-impresión. El autor cuestiona el modo en el que el poder configura el archivo, así como sus diferentes soportes y su autoridad. En relación a esta idea de archivo Guasch aclara: "De ahí que el archivo no sólo sea un conjunto de documentos reunidos y custodiados en un lugar, sino un sistema articulado de signos, sin fisuras, sin discontinuidades ni elementos distorsionadores" (Guasch, 2011, p. 166).

Foucault analiza el cambio de modelo en la estructuración del conocimiento que se ha producido en la cultura contemporánea. Esto quiere decir que determinados discursos dependen de unas condiciones reales y que son estas condiciones las que determinan su "positividad” (Foucault, 1979, pp. 214-215). Frente a este modo de articular el conocimiento, Foucault plantea el concepto de archivo. Su definición no consiste en la suma de todo el conocimiento generado por una cultura, sino en el generado por un determinado sistema de “discursividad” según sus posibilidades e imposibilidades. El archivo constituye, de este modo, un sistema que organiza enunciados mediante relaciones múltiples que evitan la linealidad o el amontonamiento (Foucault, 1979, p. 220). Este análisis lo aborda Foucault a través del concepto de "arqueología”, que pretende poner de manifiesto las reglas que determinan las prácticas discursivas. Para Foucault la arqueología "es la descripción sistemática de un discurso-objeto" (Foucault, 1979, p. 235). A través de la arqueología no se busca una reinterpretación del conocimiento, se trata, más bien, de reconstruirlo a través de una categoría de presente donde las diferencias - de pensamiento- no sean un obstáculo. Guasch, aclara que la idea de arqueología en Foucault, refiere a describir los documentos como método de interrogación y con la intención de reescribir la historia (Guasch, 2011, p. 48). De este modo se descentraliza el conocimiento, al no existir la primacía de un discurso sobre otro.

Esta forma de entender el conocimiento está en relación con el concepto de rizoma desarrollado por los filósofos Félix Guattari y Gilles Deleuze, para quienes el conocimiento se constituye como una conexión heterogénea de diversas multiplicidades donde un punto puede estar conectado con cualquier otro. En este modelo, el conocimiento está descentralizado, fragmentado, donde no existe un punto estable de referencia, tampoco un punto de inicio, ni de final. 
Así, lo relevante de su estructura son las conexiones que se establecen, no los puntos que se conectan que a su vez se caracterizan por su capacidad de 'ruptura' y 'reubicación'. Como sostienen los autores, es la transversalidad la que organiza el conocimiento (Deleuze \& Guattari, 2002, pp. 13-15). En relación a la fotografía, el concepto de rizoma nos sirve para comprender el modo en el que las imágenes fotográficas se organizan unas con otras.

\section{Sistematización, acumulación y proceso}

En este apartado analizaremos el proceso de fragmentación a través de tres modelos, que ilustramos con el trabajo de fotógrafos de referencia: sistematización, acumulación y proceso. Otras estrategias como el recurso al índice, el sistema modular, la secuencialidad, no son objeto de estudio para esta investigación. Ponemos el foco en las estrategias de sistematización, acumulación y proceso que cobran especial relevancia en las prácticas conceptuales desarrolladas a partir de los años 60. Este proceso de fragmentación de la imagen fotográfica es el resultado de una característica común: la fotografía funciona como documento. Como explica Morgan: "Así la fotografía en el arte conceptual se convierte en el reverso de un signo por su capacidad de funcionar a la vez dentro y más allá de las limitaciones estructurales de su capacidad documental" (Morgan, 2003, p. 127). Estas prácticas seleccionan un objeto o sujeto y lo fotografían de forma obsesiva creando una serie de imágenes de un solo tema que se convierten en documentales y estéticas al mismo tiempo. Existe a su vez una resistencia emocional (por parte del autor) que deriva en lo neutral de la representación. Estos modelos son, por lo tanto, tres respuestas a un estado de construcción y reconstrucción permanentes que impone la posmodernidad. La elección de los mismos, entendidos como estrategias para la conformación de la imagen fotográfica, se justifica en las posibilidades de investigación que cada uno de ellos ofrece a los creadores para llegar a expandir el concepto de lo fotográfico. No siendo las únicas estrategias que permiten abordar hoy la creación fotográfica con este fin, sí tienen en común la vinculación con la realidad contaminada, dinámica y líquida de nuestro tiempo. 
El primero de los modelos, refiere a la fotografía sistemática, que se define por el uso de un método establecido con anterioridad a la toma de la imagen. En una fotografía realizada con este sistema, las diferentes partes fotográficas son fragmentos de lo real, y tras un posterior reordenamiento se configurarán en el cuerpo de la obra.

El trabajo fotográfico del médico y criminólogo Cesare Lombroso pretende definir distintas tipologías de criminales. Las imágenes fotográficas son utilizadas a modo de pictogramas en los que se ilustra una tipología concreta de criminal. El carácter sistemático deriva no del método que utiliza sino de las tomas que practica a los sujetos, para expresar lo que ocultan las apariencias de los retratados según los modelos fisionómicos (F1).
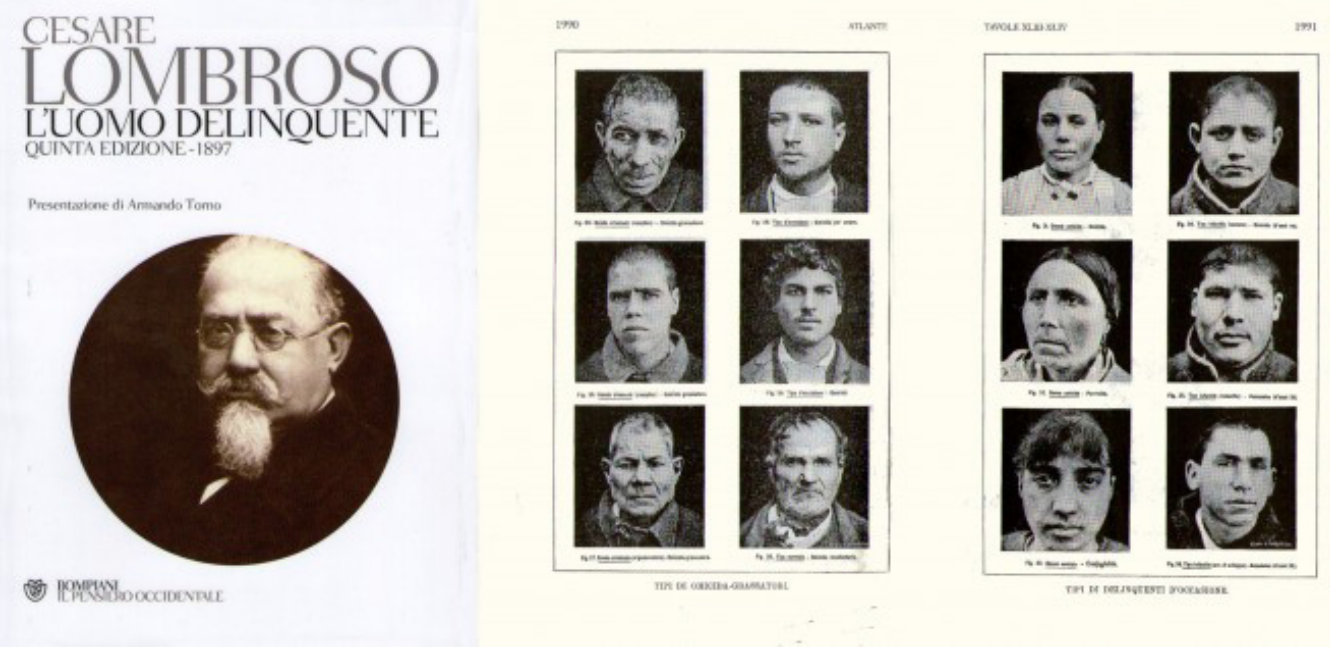

F1. Cesare Lombroso, L'uomo Delinquente, 1897. http://www.mamurio.it/back/wpcontent/uploads/Cesare-Lombroso.- Luomo-delinquente-691x324.jpg

El también médico y antropólogo Alphonse Bertillon genera un sistema de fichaje policial que le permite identificar a sujetos peligrosos. La fotografía en sí misma tiene un valor secundario para Bertillon, le interesa como documentación a partir de mediciones antropométricas de la cabeza y las manos. Llega a inventar, para la identificación de delincuentes, la ficha policial, compuesta por un retrato de frente y otro de perfil caracterizados por su neutralidad e inexpresividad. Bertillon relaciona la antropometría, práctica de carácter utilitario, con la estética del registro. Motivo por el cual su interés 
principal queda centrado en el punto de vista científico y policial. Su método simplifica y reduce el cuerpo humano a una representación sistemática y mesurable, que Bertillon denomina "fotografía métrica” (Caswell, 2015, p. 41), con la que consigue objetividad y normalización de los sujetos retratados.

En esta misma línea están las imágenes realizadas por el antropólogo y fotógrafo Francis Galton. Mediante la composición, en una sola imagen, de diferentes negativos en los que se representan sujetos criminales, pretende conseguir una imagen genérica y abstracta de los representados. Las imágenes están tomadas desde un mismo punto de vista frontal y con una misma distancia entre el sujeto fotografiado y la cámara. La superposición de los negativos genera alrededor de los sujetos fotografiados un halo que difumina y produce imprecisión e indiferencia en la representación, un efecto que otorga al resultado una cierta artificialidad.

El segundo modelo se basa en la acumulación de material fotográfico y que se configura a través del acopio del mismo sin un ordenamiento determinado a priori. La lógica en su ordenamiento responde únicamente al proceso de situar una imagen junto a la otra, y no se lleva a cabo de acuerdo a un sistema. Se trata de una mera sucesión de fragmentos de la realidad, donde el factor tiempo es anulado, queda en suspenso.

El pintor Gerhard Richter hace uso de este método con el proyecto Atlas (F2). A través de la acumulación y archivo de imágenes fotográficas, procedentes de diversos medios, pretende conceptualizar la idea de memoria. Como escribe el historiador de arte alemán Helmut Friedel (2006):

Desde comienzos de la década de los sesenta, Gerhard Richter coleccionó fotografías amateurs, iconos cotidianos, instantáneas de álbumes familiares así como «fotos de reportajes» de periódicos y revistas en las que estaba reflejado «el mundo». La fuente de las fotografías no parece haber preocupado particularmente a Richter. [...] Imágenes de acontecimientos históricos, políticos y eventos sociales, retratos de ídolos, estrellas y símbolos de estatus, pero también imágenes de desastres y accidentes, aviones y coches -este caleidoscopio de imágenes forma el núcleo principal del Atlas que en un principio 
era seminalmente una colección de algo así como fotos «ingenuas», inconfundiblemente fechadas por los signos del tiempo (Friedel, 2006, pp. 7-8).

De este modo Richter acumula a través de la idea de archivo una obra que responde a historias personales, políticas y sociales. En este archivo, las imágenes se relacionan de forma no lineal, dado que no existe un solo orden, sino diversos. Como comenta Guasch, Richter hace que sus imágenes se agrupen "en figuras distintas, se compongan las unas con las otras según relaciones múltiples y se mantengan o desaparezcan según regularidades específicas" (Guasch, 2011, p. 55). De este modo, en los paneles, estructurados mediante una cuadrícula, que divide y organiza las imágenes, se genera un sistema de organización homogéneo del que se desprende su carácter conceptual.

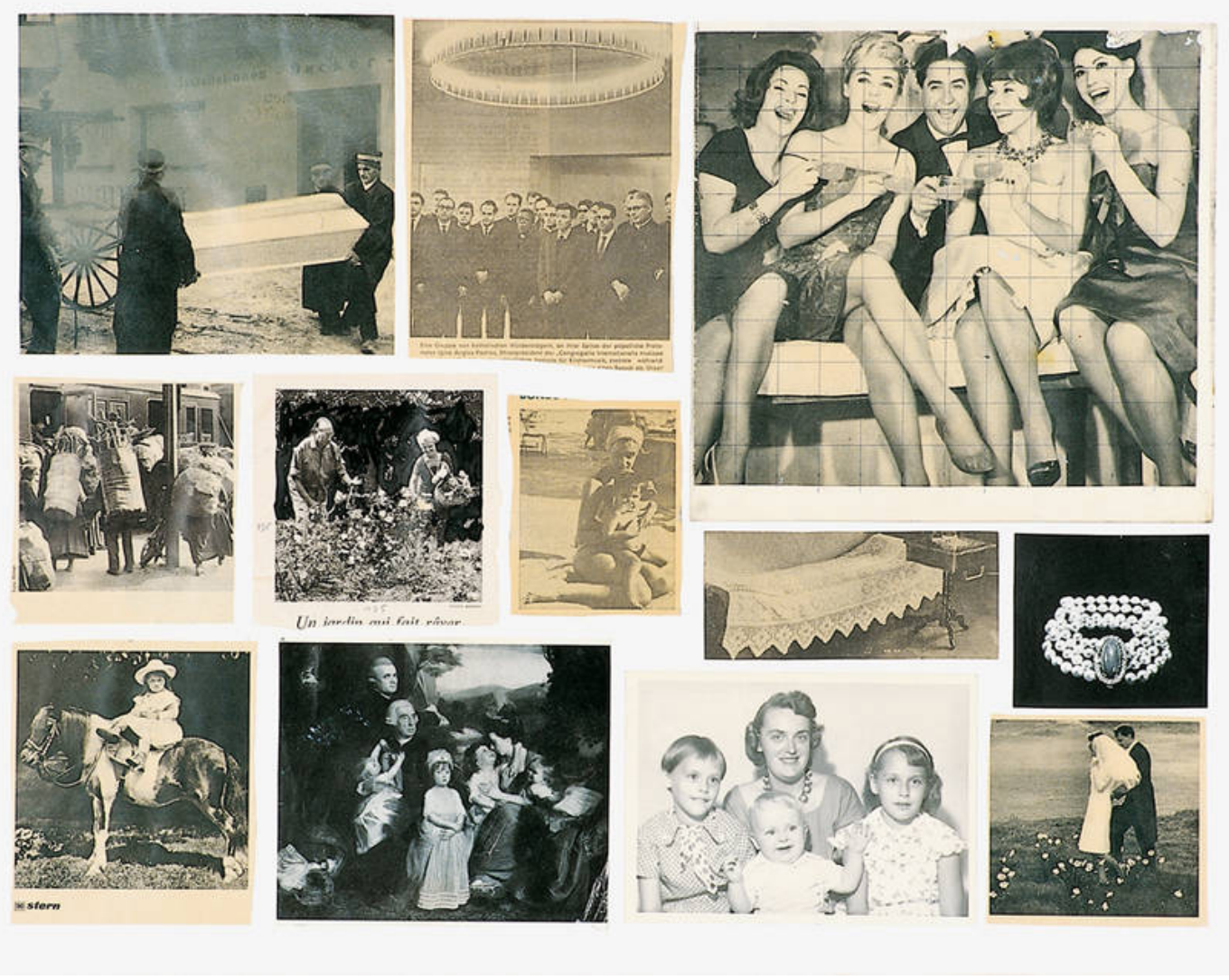

F2. Gerhard Richter, Atlas, Plate 9, 1962-1968.

http://www.skd.museum/typo3temp/pics/1dd13aa6e8.jpg

Esta distribución genera una relación dialéctica entre las imágenes a través de los espacios y tiempos en los que se desarrollan. En cierto modo, la estructura 
de conocimiento que expone es similar a la idea de rizoma de Deleuze y Guattari que hemos comentado anteriormente. La reorganización visual se construye de forma discontinua y fragmentada y el conjunto de fotografías, de carácter heterogéneo, genera una lectura cambiante.

Christian Boltanski a través de la acumulación repetitiva de documentos fotográficos desarrolla un programa conceptual, para centrarse en el proceso de creación de la obra antes que en su materialización. Toma como punto de partida el método de investigación arqueológica, lo que le permite indagar en aspectos relacionados con la memoria personal y colectiva. Boltanski explica en la entrevista que le realiza la profesora de Historia del Arte del University College London, Tamar Garb (1997):

Parte de mi trabajo ha sido sobre lo que puedo llamar «pequeños recuerdos». La gran memoria es recordada en libros y la pequeña memoria trata de pequeñas cosas: trivialidades, bromas. [...] intentar de preservar los «pequeños recuerdos», porque a menudo cuando alguien muere, esa memoria desaparece. Todavía, esa «pequeña memoria» es lo que hace a las personas unas diferentes de otras, únicas. Estos recuerdos son muy frágiles; yo quería salvarlos (Semin, Garb \& Kuspit, 1997, p. 19).

Existe un interés en la obra de Boltanski por el carácter material de los objetos que hace alusión a la memoria como hecho cultural. Consecuencia de ello, la presentación y exposición de sus trabajos se acerca al modelo museístico, proporcionando al espectador una lectura contextual y cultural de la fotografía. A través de la apropiación de fotografías, las imágenes pasan a ser pruebas de un valor etnográfico, nunca serían consideradas 'fotografías' en sí mismas - que por otra parte no realiza el propio autor, quien más que un fotógrafo se considera un "reciclador". Para Boltanski mirar una fotografía supone creer inicialmente que es real, si bien no llega a serlo, aunque sí tiene una estrecha relación con lo real. La conexión con la realidad, cuando se pinta un retrato, no es tan estrecha - sostiene el autor-, con una fotografía, en cambio, el espectador puede sentir que las personas fotografiadas "estaban allı́”. Lo cual conlleva una forma de abordar el medio que destaca por su carácter científico y objetivo. 
Finalmente, exponemos el modelo procesual donde intervienen diversos elementos, entre ellos el principal: la idea de 'ir hacia delante', que persigue irremediablemente el concepto de tiempo. Un concepto que se muestra evidente en la imagen fotográfica a través de su representación fragmentada, como intervalos o distancias entre momentos representados.

Entre los fotógrafos que han abordado este modelo procesual de representación encontramos a Etienne-Jules Marey. Sus investigaciones destacan por ser pioneras en el estudio del movimiento, y están basadas en la superposición de distintas tomas realizadas de manera que represente la realidad de forma procesual. Para el desarrollo de sus imágenes lleva a cabo la invención del llamado fusil fotográfico, que "permitía sacar doce instantáneas en un segundo, cada una con una exposición de 1/720 de segundo" (Sougez, 1994, p. 286). De este modo Marey logra descomponer el movimiento del cuerpo humano para llevar a cabo su análisis de forma objetiva.

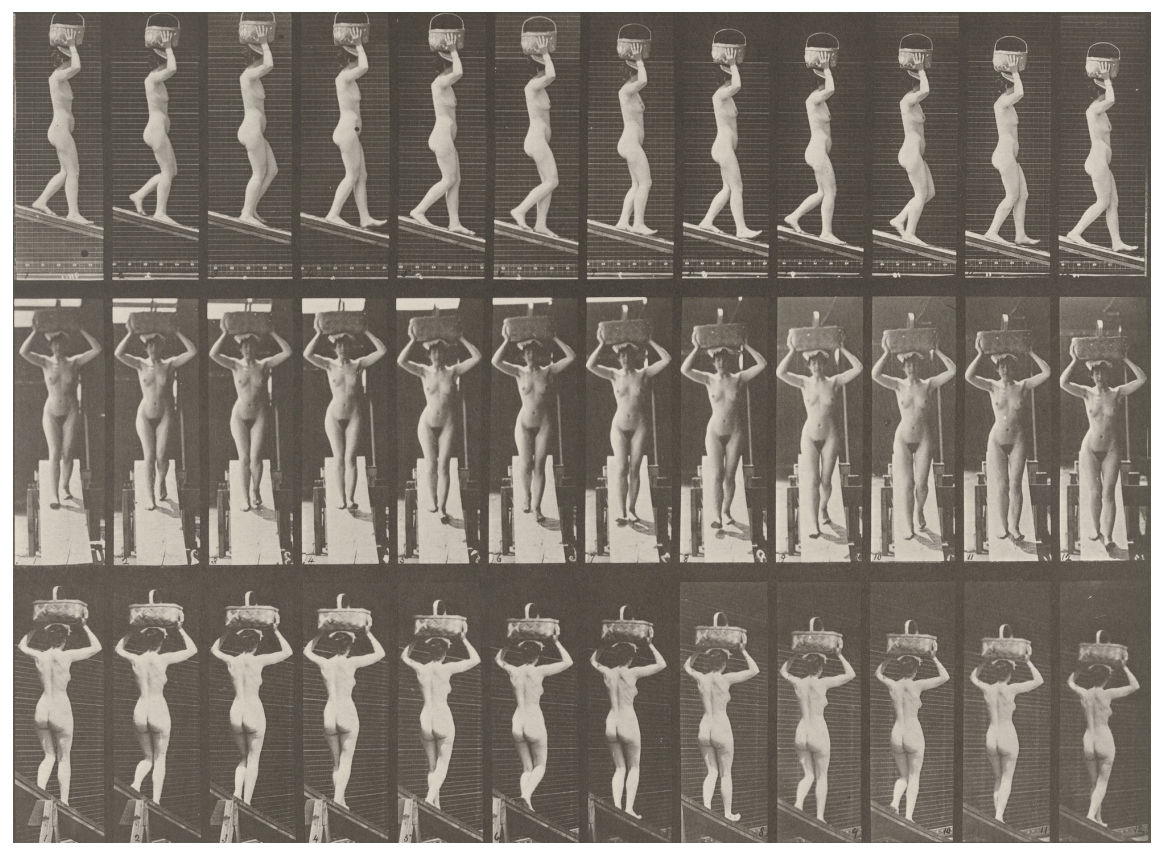

F3. Eadweard J. Muybridge, Woman Descending an Incline with a 2O-lb. Basket on Head, Hands Raised: Plate 124 from Animal Locomotion, 1887. http://www.moma.org/collection/works/44135?locale=es

Sincrónico en el tiempo, encontramos al fotógrafo e investigador Eadweard Muybridge, cuyas imágenes responden a estudios fotográficos para la representación del movimiento, y tienen un carácter más artístico y estético que 
científico (F3). De este modo, otorga mayor artisticidad al resultado mediante líneas dibujadas en los espacios representados, que sugieren un pseudo uso científico y establecen diferentes relaciones de espacio y tiempo, evidenciando el carácter procesual del producto. Las representaciones corresponden a series de fotografías presentadas una tras otra, a modo de narración, de distintos ejercicios realizados por los modelos que son congelados de forma aislada en cada imagen de las fases del movimiento.

\section{Creación fotográfica en Andalucía}

En este apartado abordamos los modelos de sistematización, acumulación y proceso empleados como métodos por tres fotógrafos andaluces. Si bien, la obra de cada uno de estos creadores ofrece particularidades en la concepción de la idea y en los resultados de la imagen generada, como veremos seguidamente, el patrón discursivo que les une es el uso de la documentación fotográfica y su fragmentación.

La fotógrafa malagueña Clara González Ortega (Málaga, 1985), en 2011 presentaba la serie Estudios del cielo (F4). Un proyecto que refleja el interés de la autora por el método de sistematización a través de grandes composiciones fotográficas, que representan diferentes momentos temporales, de lo cambiante, de lo transitorio. La serie nos ofrece la experiencia de lo temporal y el modo en el que esta afecta a su percepción y representación. Sistemáticamente, durante más de un mes, cada día la autora fotografió el cielo desde el mismo lugar y a la misma hora (11:0o a.m.) fraccionándolo y tomando imágenes hacia los cuatro puntos cardinales. La recopilación de las imágenes dio como resultado la catalogación de forma física del tiempo y el espacio a través de su materialización visual.

Fotografía, tiempo y fragmentación son los materiales con los que la artista trabaja, para llegar a una imagen fotográfica taxonómica o científica. El crítico Sema D’Acosta (2012) explica al respecto:

Este afán de González Ortega por captar la duración de las cosas se traduce en una sucesión de imágenes que retratan siempre el mismo espacio en momentos 
contiguos. El resultado de este proceso es una muestra cromática, parecida a las primeras creaciones, que dependen de la luz del día o la climatología, una fotografía que retrata las variaciones de la naturaleza (D'Acosta, 2012, p. 120).

Pero, en su intención por materializar la representación del tiempo, percibimos que está coartada por las contradicciones que surgen de las circunstancias cambiantes que se producen en el transcurso vital. La cuestión de la representación temporal es abordada como una imposibilidad determinada por el corte que efectúa la cámara fotográfica. Llevar a cabo el acto fotográfico implica la interrupción tanto del transcurso vital (lo subjetivo), como del espacio y tiempo real (lo objetivable).

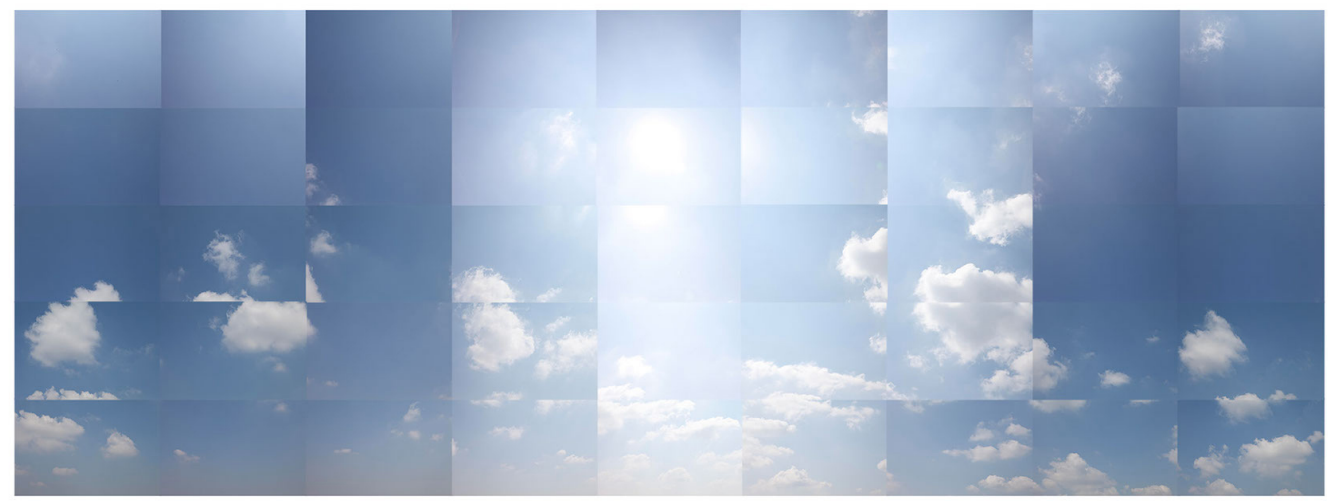

F4. Clara González Ortega, Serie Estudio del cielo-Roma, 2011.

http://claragonzalezortega.blogspot.be/p/estudio-del-cielo.html

La medición y representación del tiempo y el espacio a través de la fotografía es un tema que se repite a lo largo de la historia del medio fotográfico. Tiene su raíz en la concepción objetiva que acompañó a la fotografía desde sus primeros años de desarrollo. Determinada por el "gesto radical del corte", según Philippe Dubois (1994):

Después del índex, el corte. Después de la cuestión de la relación de la imagen con lo real, la cuestión de su relación con el espacio y el tiempo. Aquí todo gira alrededor de la noción de corte. La imagen fotográfica, en tanto es indisociable del acto que la constituye, no sólo es una huella luminosa, es también una huella 
trabajada por un gesto radical, que la crea por entero de un solo golpe, el gesto del corte, del cut, que hace caer sus golpes a la vez sobre el hilo de la duración y en el continuum de la extensión (Dubois, 1994, p. 141).

En el mismo sentido planteado por Dubois, el trabajo de González Ortega fija e inmoviliza el transcurso espacial y temporal, mediante instantes únicos, que recortan 'porciones' de espacio y tiempo para objetivarlos.

El sociólogo Norbert Elias define dos concepciones de "tiempo": como dato natural y "objetivo", al existir con independencia de la existencia humana, y otra concepción que describe como "simple representación" que es "subjetiva” y por tanto "anidada en la naturaleza humana" (Elías, 1989, pp. 14-15). En ambos casos el tiempo es una referencia natural. La cuestión de cuál de las dos ideas prevalece es abordada en las fotografías de la artista malagueña al situar ambas concepciones en un mismo plano. Plantea cómo ser humano y tiempo son parte integrante de la misma naturaleza y por lo tanto no pueden situarse fuera de ella de manera independiente y objetiva ya que se trata de construcciones subjetivas. González Ortega representa en sus fotografías un tiempo que se mueve a través de estas dos polaridades opuestas.

En relación con las fotografías de Eadweard Muybridge, González Ortega descompone el tiempo en secuencias fotográficas que organiza geométricamente en retículas. Igualmente, su trabajo se relaciona estrechamente con el realizado por el artista holandés Jan Dibbets (F5), cuyo interés se centra en la deconstrucción y transformación espacio-temporales. Con obras como Waterstructures (1973) y Colorstudies (1976), Dibbets cuestiona la capacidad documental de la fotografía en la misma línea que las imágenes de González Ortega, en las que la fotografía actúa como un signo que atiende a un referente no relacionado con él (Morgan, 2003, pp. 122-123). 


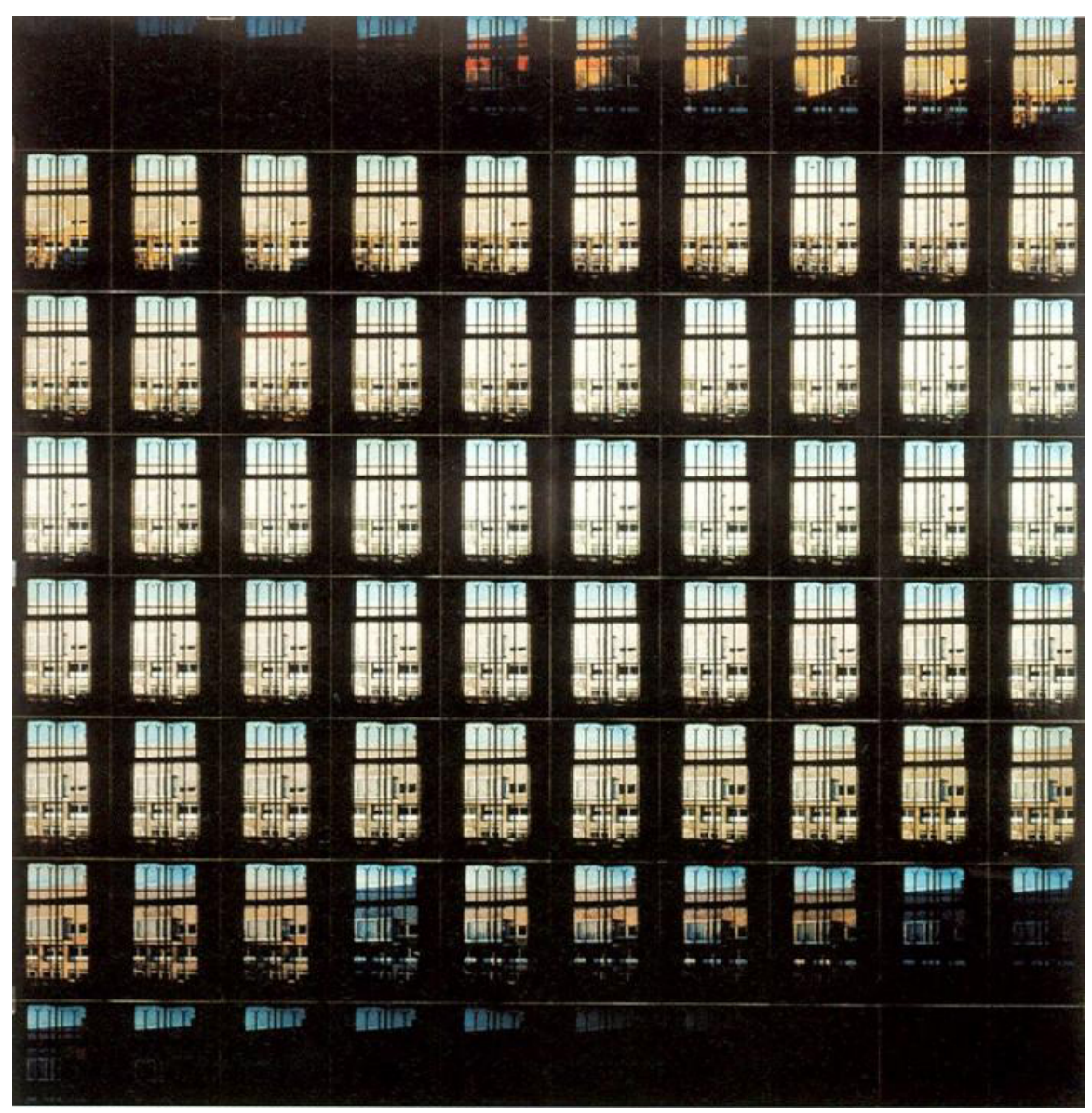

F5. Jan Dibbets, The Shortest Day at the Van Abbemuseum, Eindhoven, 1970. http://www.artdiscover.com/en/artists/jan-dibbets-id1005

Gabriel Campuzano (Sevilla, 1955) es arquitecto y fotógrafo. Aborda la temática del espacio en relación con la arquitectura mediante imágenes polaroid, así como la identidad, la memoria, el tiempo; hace uso de la idea de archivo, "aplicada al registro de la memoria propia mediante la documentación de experiencias biográficas" (Rubio, 2013, p. 118) -en algunos de sus proyectos. La estética final, con aspecto difuso o fantasmal, deviene por el resultado "pictorialista" que adquieren las imágenes; tiene como intención el registro de la memoria, el borrado de la autoría y la disolución del estilo. En la imagen, además, hace acto de presencia el dibujo (por los esquemas) así como la escritura (por la inclusión de títulos y del lugar donde fueron tomadas las imágenes). En suma, las fotografías de Campuzano destacan por el halo de misterio generado por un proceso de deconstrucción aplicado a la imagen fotográfica (F6). 


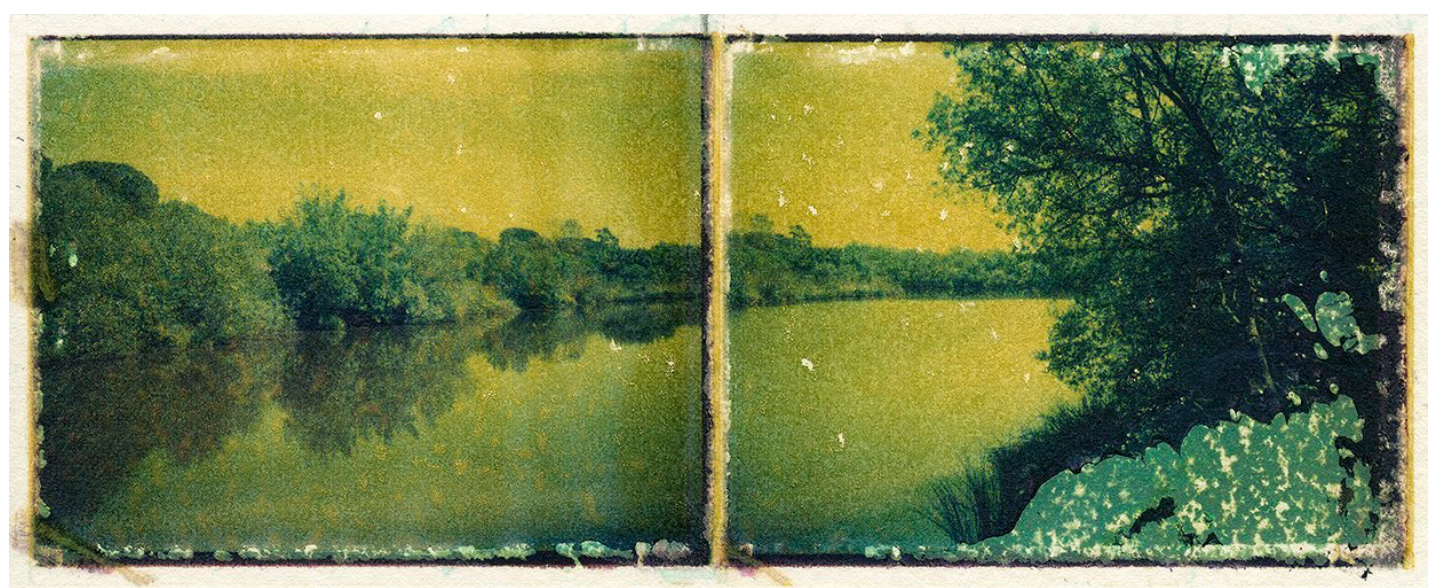

F6. Gabriel Campuzano, Laguna del Acebrón, 1996.

http://www.gabrielcampuzano.com/www.gabrielcampuzano.com/Archivos_G.html\#8

A partir del año 2010 Campuzano desarrolla instantáneas de forma sistemática que agrupa con el nombre de Archivos de una Memoria y que posteriormente utiliza para el desarrollo de proyectos visuales de carácter narrativo. El artista aborda el archivo como un contenedor de registros en el que acumula material fotográfico. Guasch, en relación con los principales proyectos de archivo de principios del siglo pasado de autores como Walter Benjamin, Aby Warburg, August Sander, Karl Blossfeldt y Albert Renger-Patzsch, señala que "el archivo contemporáneo ha funcionado a través de dos máquinas o modus operandi: la que pone énfasis en el principio regulador del nomos (o de la ley) y del orden topográfico, y la que acentúa los procesos derivados de las acciones contradictoras de almacenar y guardar, y, a la vez, de olvidar y destruir huellas del pasado, una manera discontinua y en ocasiones pulsional que actúa según un principio anómico (sin ley)" (Guasch, 2011, p. 15). El trabajo de archivo se centra, precisamente, en esa acción de 'almacenar y guardar', 'olvidar y destruir', para devenir en montaje narrativo.

Campuzano archiva sus imágenes fotográficas de acuerdo a unos criterios específicos de acumulación: organiza sistemáticamente las imágenes por géneros que posteriormente utiliza para proyectar una nueva narración y con ello un nuevo significado. Esta capacidad de la imagen fotográfica para servir de soporte de nuevos discursos tiene su base en el carácter indicial de la fotografía, que permite la construcción de nuevos mensajes. Como señala Robert C. Morgan (2003): 
La fotografía puede representar un acontecimiento concreto, puede a la vez proyectar otro referente que constituye la base de la intencionalidad del artista. De manera oblicua, la inversión del signo documental opera de una forma que se relaciona con los anuncios y otras formas de publicidad; pero en contraste con los anuncios, el arte conceptual no usa un producto sino una idea, a menudo un discurso dialéctico, como su referente (Morgan, 2003, p. 124).

Es en el proceso de montaje desde donde aparece el significado de la obra. Las imágenes que Campuzano registra muestran una huella, nos dicen que algo o alguien estuvo en un lugar determinado y en un momento concreto. Sobre la capacidad de evocación que tienen las imágenes, Serge Tisseron (2000) señala:

La fotografía no sólo nos permite toparnos con el recuerdo visual de un acontecimiento, sino también con lo que son sus diversos componentes sensoriales. [...] Si la fotografía [de una reunión familiar, por ejemplo, suscita] ciertos recuerdos no visuales de un acontecimiento es, claro está, por su proximidad con el recuerdo visual (Tisseron, 2000, p. 124).

El archivo le permite a Campuzano recurrir a imágenes fotográficas que contienen el registro de su memoria para, mediante la reordenación de las imágenes fotográficas contenidas en el archivo, generar un nuevo discurso.

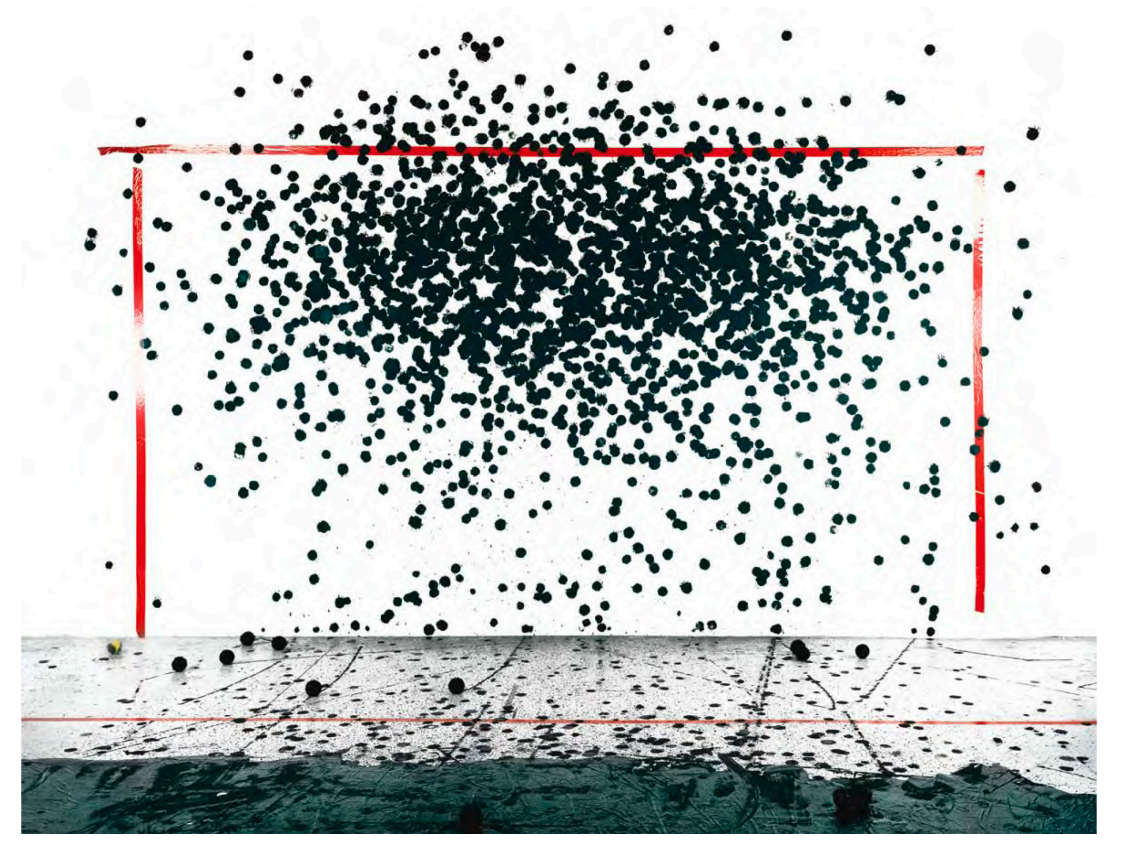

F7. Juan Carlos Bracho, Sólo cerrando puertas detrás de cada uno se abren ventanas al porvenir \#12, 2006. http://www.juancarlosbracho.com/proyectos/o9/donner.html 
Finalmente debemos destacar el estilo "pictorialista" de las imágenes fotográficas. Un tratamiento que responde, según el historiador de arte, Marc Melón a una intención doble: “sepultar lo real y disfrazar la imagen” (Lemagny, 1988, p. 82). La fotografía pictorialista tiene como finalidad convertir lo real en imagen. Esta es la estrategia que sigue Gabriel Campuzano en sus fotografías para convertir las imágenes en memoria. La fotografía pictorialista se interesa por la expresión de la idea de lo real y no por representar lo real de forma natural. Como consecuencia, la fotografía abordada de este modo posee una finalidad ideológica. Con este tratamiento Campuzano logra conectar la imagen real con la memoria, se trata de una mirada subjetiva despojada de excedente de realidad para quedarse únicamente con lo esencial.

Para finalizar, la obra del artista Juan Carlos Bracho (Cádiz, 1970) destaca por su carácter procesual, el uso de pequeños gestos repetitivos y la adición sistemática de elementos, todos ellos de naturaleza minimalista. El artista utiliza el dibujo - que juega un papel fundamental como generador de ideas y creador del espacio conceptual- la instalación, la escultura, la performance, los libros de artista, el vídeo y la fotografía, con un marcado interés por el espacio y por la experiencia del espectador frente a él.

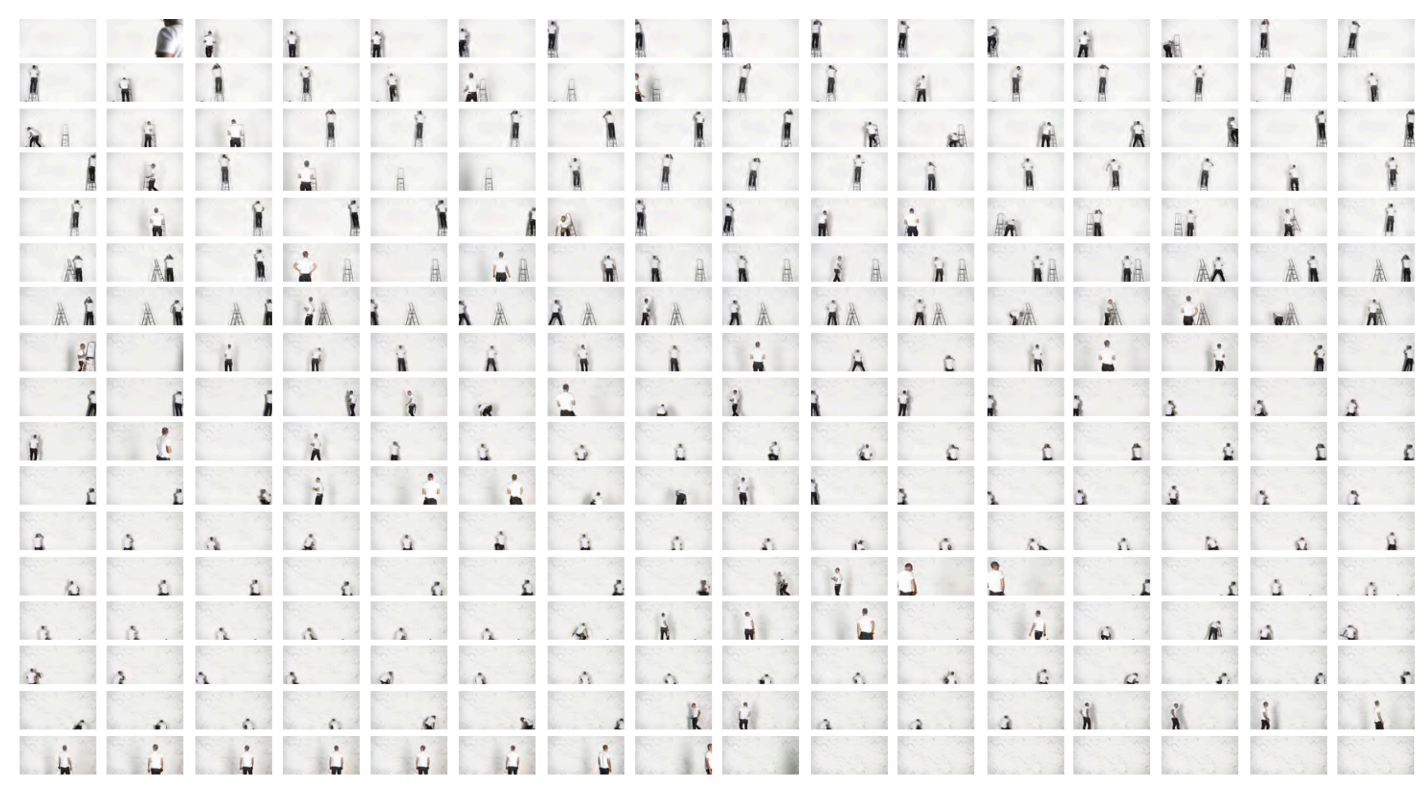

F8. Juan Carlos Bracho, Félix y su amiga F (Yo también lo haría), 2009. http://www.juancarlosbracho.com/proyectos/o6/felix.html 
Bracho otorga una gran importancia al proceso y al modo como la obra se construye a través del tiempo. La fotografía registra la repetición y la sistematización de estos gestos para construir su discurso. Por un lado, la fotografía registra el carácter procesual, el desarrollo de la obra y su carácter sistemático, por otro, evidencia su relación con la realidad.

Juan Carlos Bracho realiza en 2005 una acción que es grabada en vídeo. Esta acción consiste, en lanzar una pelota de tenis teñida con tinta negra de forma repetida sobre una pared blanca (F7). Esta acción tiene como particularidad el carácter repetitivo de un gesto intranscendente que construye en el transcurso de la misma la imagen resultante. Destaca el interés del artista por el carácter procesual en su desarrollo, la fragmentación del tiempo y la representación del espacio.

La imagen fotográfica funciona como representación de la fragmentación del tiempo y el modo como se construye esta a través de las paulatinas marcas de huellas que la pelota deja en la pared blanca. Ambas representaciones se fundamentan en la noción de índice o relación indicial. Como aclara Dubois al respecto: "la imagen foto se torna inseparable de su experiencia referencial, del acto que la funda. Su realidad primera no confirma otra cosa que una afirmación de existencia. La foto es ante todo índex" (Dubois, 1994, p. 5). La atención está en el proceso mismo mediante el que se crea la imagen y que toma como punto de partida la realidad. Dubois continua:

Hay, pues, entre la fotografía y las diversas prácticas que vamos a evocar una primera relación, una aproximación primaria, a la vez fundamental y de principio, una lógica constitutiva, un epistema común, el índice, es decir, la imposibilidad de pensar el producto artístico sin inscribir en él también (más aún, sobre todo) el proceso del que es el resultado (Dubois, 1988, p. 244).

En consecuencia, para entender la relación indicial en la representación artística hay que concebirla como el resultado de un proceso. Y esto mismo es lo que sucede en el trabajo de Juan Carlos Bracho, las representaciones que se obtienen como resultado, tanto el choque de la pelota en la pared, así como la toma fotográfica, no pueden entenderse separadas del proceso mediante el que se han llevado a cabo. Es esta capacidad del signo indicial la que permite la 
reconstrucción del proceso y la que le posibilita al artista centrar su trabajo en la relación que establece la obra con el espacio y con la idea de tiempo. Es decir, la idea de proceso está estrechamente relacionado con la naturaleza de la representación fotográfica. Como declara Morgan (2003): “Deberíamos iniciar este tema con la siguiente generalización: una imagen llega a constituirse como resultado de un proceso" (Morgan, 2003, p. 119).

En el mismo sentido, las imágenes fotográficas han sido tomadas de forma sistemática, siguiendo el mismo proceso mediante el que se ha construido las huellas en la pared. Morgan (2003) explica las relaciones que la imagen fotográfica puede establecer con una concepción conceptual del arte:

La documentación fotográfica en relación con el arte conceptual puede funcionar como un proceso calculado, que emana de un sistema de percepción, o como un ritual lleno de carga emocional. Hay algunas diferencias fundamentales entre la orientación de los artistas conceptuales, que tratan con sistemas e ideas, y la de los fotógrafos, que pueden tender a insistir más en la visualización de una idea como un modo primario de representación. Hemos sugerido que lo que hace funcionar conceptualmente una afirmación o una idea dentro de un contexto artístico, se basa en la materialización de lo que puede desprenderse del mundo de acción cotidiano y recontextualizarse en forma de documentación. Al igual que sucede con las otras fotografías, las empleadas como documentos en el arte conceptual son significantes visuales (Morgan, 2003, p. 127).

El trabajo fotográfico de Bracho se construye a través de un proceso calculado y de carácter sistemático. Cabría destacar que el uso que el artista hace de la fotografía se define por su capacidad significante a través de la visualidad. La representación se convierte en signo que construye el sentido de la obra. Este mismo uso de la fotografía se repite en los diferentes proyectos de Juan Carlos Bracho, como por ejemplo en su proyecto Félix y su amiga F (F8). Encontramos de nuevo el gesto banal, repetitivo y sistemático que construye el proceso de la obra. 


\section{Conclusiones}

Fruto de la investigación realizada, la primera de nuestras conclusiones subraya que la concepción de la imagen como un todo unitario pierde su vigencia en el período posmoderno. En este sentido, el medio fotográfico es capaz de generar discursos que están fuera de una progresión lineal y lo sitúan en una posición de privilegio para la comunicación humana. Esto lo consigue mediante el recurso de la fragmentación que permite abordar la construcción de la imagen a través de la sistematización, la acumulación y el proceso. Considerando la fotografía sistemática como un método que se establece mediante una serie de reglas establecidas con anterioridad a la realización de las imágenes, la acumulación como acopio de material fotográfico sin un orden establecido a priori, y finalmente el modelo procesual en el que el conjunto de imágenes fotográficas tiene como finalidad mostrar las fases sucesivas de lo representado, evidenciando el transcurso del tiempo.

La segunda de nuestras conclusiones afirma que la fotografía permite la reorganización de la realidad a través de su naturaleza indicial, una característica que conlleva nuevos modos de archivo para la imagen a través de rupturas y reubicaciones. El carácter indicial de la fotografía, en su relación con el archivo, hace de la imagen fotográfica un elemento indisociable del proceso que la constituye. Mientras la posmodernidad se caracteriza por la destrucción y reconstrucción de los discursos en todas las esferas del conocimiento, esta capacidad de proyección del signo indicial permite proyectar nuevas narraciones que superan la dinámica posmoderna.

La tercera de nuestras conclusiones refiere a la aportación que, los artistas seleccionados, realizan en relación al modo particular con el que cada uno de ellos aborda la fragmentación, a través de los modelos de sistematización, acumulación y proceso. Cabría acentuar que estamos ante unas propuestas fotográficas que escapan a cualquier clasificación cerrada, dejando claro su carácter heterogéneo e híbrido.

En las aportaciones fotográficas de Clara González Ortega los conceptos de ‘tiempo’ y ‘espacio' refieren a una repetición sistemática, más que a un proceso 
de avance. La presentación de las imágenes en retículas y las reglas mediante las que realiza las tomas hace que la sistematización prevalezca.

Resulta evidente que las investigaciones sobre la imagen de Gabriel Campuzano surgen de la acumulación previa de material fotográfico. Prevalece en su búsqueda la idea de archivo y constatamos cómo este se constituye sin ningún tipo de orden o plan preestablecido. Es con la organización posterior de las imágenes cuando estas son sistematizadas al agruparlas en series temáticas.

Finalmente, en las fotografías de Juan Carlos Bracho prima su carácter procesual, aunque no es menos evidente un claro interés por la sistematización de las tomas fotográficas, así como por la idea de acumulación -o archivo-. En suma, consideramos que el carácter procesual es el resultado de la conjunción del modelo sistemático y de la acumulación.

\section{Referencias bibliográficas}

Caswell, M. (2014). Archiving the unspeakable. United States of America: The University of Wisconsin Press.

D 'Acosta, S. (2012). Guía de Fotografía Andaluza Actual. _o12 Stand By. Sevilla: Fundación Valentín Madariaga.

Deleuze, G. \& Guattari, F. (2002). Milmesetas. Capitalismo y esquizofrenia. Valencia: Pretextos.

Derrida, J. (1997). Mal de archivo. Una impresión freudiana. Valladolid: Editorial Trotta.

Dubois, Ph. (1998). La fotografía y el arte contemporáneo. En Lemagny, J. C. \& Rouillé, A., Historia de la fotografía (pp. 231-254). Barcelona: Ediciones Martínez Roca.

Dubois, Ph. (1994). El acto fotográfico. De la Representación a la Recepción. Barcelona: Paidós Comunicación.

Elias, N. (1989). Sobre el tiempo. México: Fondo de cultura económica.

Foster, H., Krauss, R., Bois, Y.A. \& Buchloh, B.H.D. (2006). Arte desde 1900. Madrid: Ediciones Akal.

Foucault, M. (1979). La arqueología del saber. Buenos Aires, Argentina: Siglo XXI Editores.

Foucault, M. (1968). Las palabras y las cosas. Una arqueología de las ciencias humanas. Buenos Aires, Argentina: Siglo XXI Editores.

Friedel, H. (2006). Gerhard Richter, Atlas. London: Thames \& Hudson Ltd. 
Guasch, A. M. (2011). Arte y Archivo, 1920-2010. Genealogías, tipologías y discontinuidades. Madrid: Ediciones Akal.

Jameson, F. (1996). Teoría de la posmodernidad. Madrid: Editorial Trotta.

Lemagny, J. C. \& Rouillé, A. (1988). Historia de la fotografía. Barcelona: Ediciones Martínez Roca.

Lyotard, J. F. (1994). La posmodernidad (explicada a los niños). Barcelona: Gedisa.

Morgan, R. C. (2003). Del Arte a la Idea. Ensayos sobre arte conceptual. Madrid: Ediciones Akal.

Rubio, O. M. (2013). Diccionario de fotógrafos españoles. Del siglo XIX al XXI. Madrid: La Fábrica.

Semin, D., Garb, T. \& Kuspit, D. (1997). Christian Boltanski. London: Phaidon Press Limited.

Sougez, M. L. (1994). Historia de la fotografía. Madrid: Cátedra.

Tisseron, S. (2000). El misterio de la cámara lúcida: fotografía e inconsciente. Salamanca: Salamanca Ediciones Universidad de Salamanca. 